DOI: $\underline{\text { http://doi.org/10.21698/simi.2018.ab23 }}$

\title{
CONCEPTUAL MODEL REGARDING THE MANAGEMENT OF MAIN FLOW WASTE IN THE CONTEXT OF CIRCULAR ECONOMY
}

\author{
Lidia Kim, Bogdan Stanescu, Agnes Serbanescu, Adriana Cuciureanu, Madalina Arama \\ National Research and Development Institute for Industrial Ecology-ECOIND, 71-73 \\ Drumul Podu Dambovitei, district 6, 060652, Bucharest, evmt@incdecoind.ro, Romania
}

Keywords: conceptual model, circular economy, waste, management

\section{Introduction}

With the exception of certain categories of high-value waste, the European waste management sector could be described as the "collection and disposal" operation, the economy being linear with a negative impact on the environment and on human health.The need to implement a circular economy is an essential element in the development of a sustainable, efficient and competitive economy in terms of resources. The center of the concept of circular economy is to maintain the value of materials and products as much as possible. This aspect contributes to minimizing the need to introduce new energy and new materials. Thus, the pressure on the environmental regarding the life cycle of products is reduced starting from resources to extraction, production and them using.

The main objective of the paper is to elaborate a conceptual model for the management of some main categories of wastes in the context of the circular economy.

\section{Main waste streams in the context of circular economy}

Within the Package of Circular Economy proposed by the European Commission (COM (2015) 614), five essential waste streams are distinguished:

Municipal waste - is household waste, as well as other wastes that, due to their nature or composition, are similar to household waste. Typically, the mixed and dispersed nature of municipal waste makes it difficult treatment them. Concerning waste hierarchy, the options have generally been limited to storage and in the last decades to incineration operations.

Packaging waste - Directive 1999/31/EC on packaging establishes objectives and collection schemes for the recovery of packaging materials. Also, emphasis is placed on measures aimed to limiting the generation of packaging waste.

Food waste - these are currently managed to reduce the amount of biodegradable waste entering the landfill. Thus, was developed collection sistems of biodegradable mixtures (including food waste) and have been found the alternative management options.

Biowaste and residues-these include not only food waste but also residues from agriculture, forestry, fish farming and animal residues.

Critical raw materials - chemical elements with high-value and platinics metals present in WEEE (waste of electronic and electrotehnic equipment) and certain types of spent batteries, represent a special objective in their recovery processes. 


\section{INTERNATIONAL SYMPOSIUM "THE ENVIRONMENT AND THE INDUSTRY", SIMI 2018, BOOK OF ABSTRACTS}

\section{Conceptual model for the management of main waste streams}

Figure 1 presents a conceptual model based on optimal recovery and recycling methods for the main categories of waste in the context of circular economy.
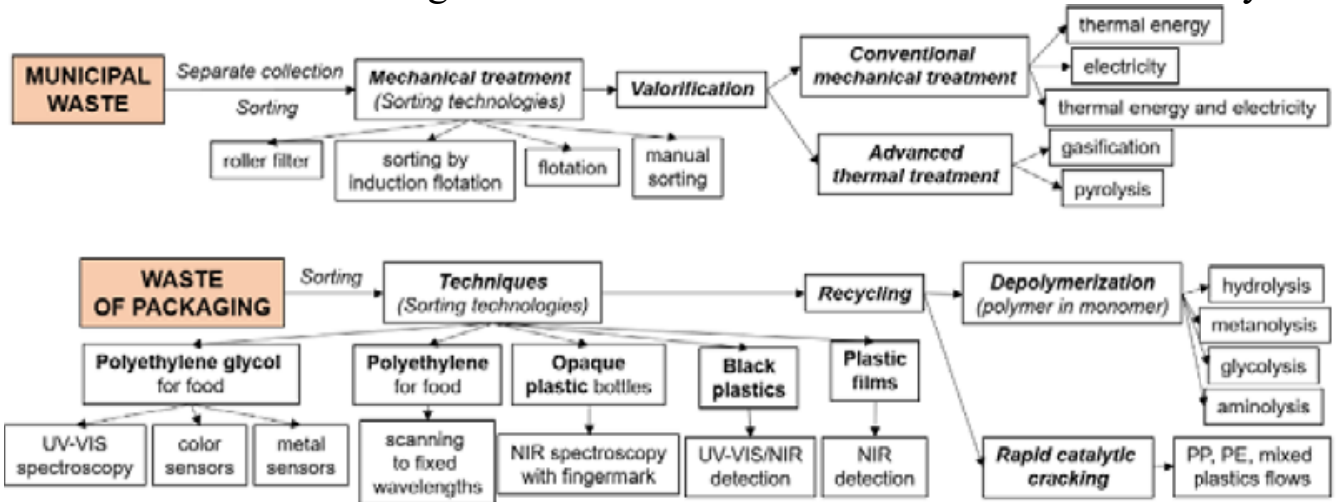

\section{Biological waste and residues} (including food waste)
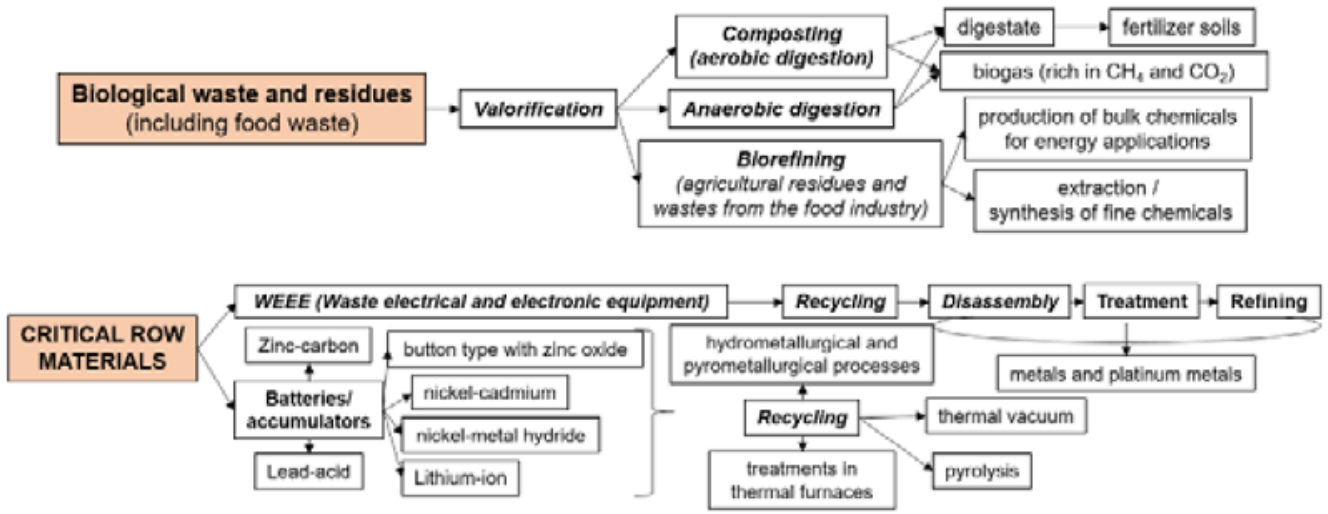

Figure 1. Conceptual model of waste management

\section{Results and conclusions}

Municipal waste - the most important step in achieving the ultimate goal of recovery is separate collection. There are functional sorting stations in many EU Member States, but they can not cover the entire amount of waste generated each year. In this respect, efforts are being made at both European and national level to awareness raising populations to the separate collection of municipal waste.

Packaging waste - in some EU Member States, there are sorting stations only for certain categories of waste. In this respect, it is necessary to extend sorting techniques in all Member States of the European Union to all categories of packaging waste.

Biological waste (including food waste) - there are several approaches to managing and capitalizing on such waste, including recovery through aerobic and anaerobic digestion and bio-refinery technologies.

Waste containing critical raw materials - are needed reliable technologies for recovering metals from WEEE and other more complex waste streams. Their recovery rate is very low, reaching only up to $10 \%$ of the total waste material generated. 